\title{
PORT SITE RECURRENCE AFTER LAPAROSCOPIC ADRENALECTOMY FOR METASTATIC MELANOMA
}

\author{
PEDRO SARAIVA, HENRIQUE RODRIGUES, PAULO RODRIGUES \\ Albarran Institute of Urology, Rio de Janeiro, RJ, Brazil
}

\begin{abstract}
Port site metastasis after adrenal surgery is a rare entity. We describe the case of a 70-yearold man with a solitary adrenal metastasis from malignant melanoma, which was laparoscopically removed. Twelve months later, he presented a recurrence near one of the laparoscopic port sites. This lesion was surgically removed and after a 18-month follow-up, the patient presents no evidence of disease.
\end{abstract}

Key words: adrenal gland neoplasms; laparoscopy; melanoma; metastasis

Int Braz J Urol. 2003; 29: 520-521

\section{INTRODUCTION}

The laparoscopic approach is currently the treatment of choice for the management of adrenal masses, especially in patients with adrenal metastases. Port site metastases after laparoscopic surgery are a matter of concern especially in abdominal cancer surgery (1). Port site metastasis after adrenal surgery is a rare entity. We present a case of a 70-year-old man with port site recurrence after laparoscopic adrenalectomy for removal of a metastatic melanoma to the right adrenal gland.

\section{CASE REPORT}

A 70-year-old man with a history of multiple melanoma resections including skin and pulmonary lesions during the last 25 years was found to have a right adrenal lesion on abdominal computerized tomography performed during follow-up. After staging, no other disease sites became evident and the patient undergone a transperitoneal laparoscopic right adrenalectomy. The specimen was removed intact through the right hand port, after entrapment in a surgical impermeable bag. Pathological analysis demonstrated a metastatic melanoma to the right adrenal gland. One year later, the patient presented a $1.5 \times 1$ $\mathrm{cm}$ hiperpigmented area close to the scar of the port site used for the specimen extraction (Figure-1). He was then submitted to resection of the lesion and port site scar. The resection included all layers of the abdominal wall, from the skin to the peritoneum, with a $3 \mathrm{~cm}$ surgical margin. The pathological analysis of this specimen also demonstrated a metastatic melanoma infiltrating the muscle layer of the abdominal wall. The skin layer was tumor free. After 12 months of follow-up, the patient presents no evidence of disease.

\section{COMMENTS}

From 1.5 to $8.6 \%$ of the metastatic adrenal lesions are malignant melanomas. These lesions are generally asymptomatic and incidentally finding. In patients with isolated adrenal metastasis or limited extra-adrenal sites of the disease, curative resection 


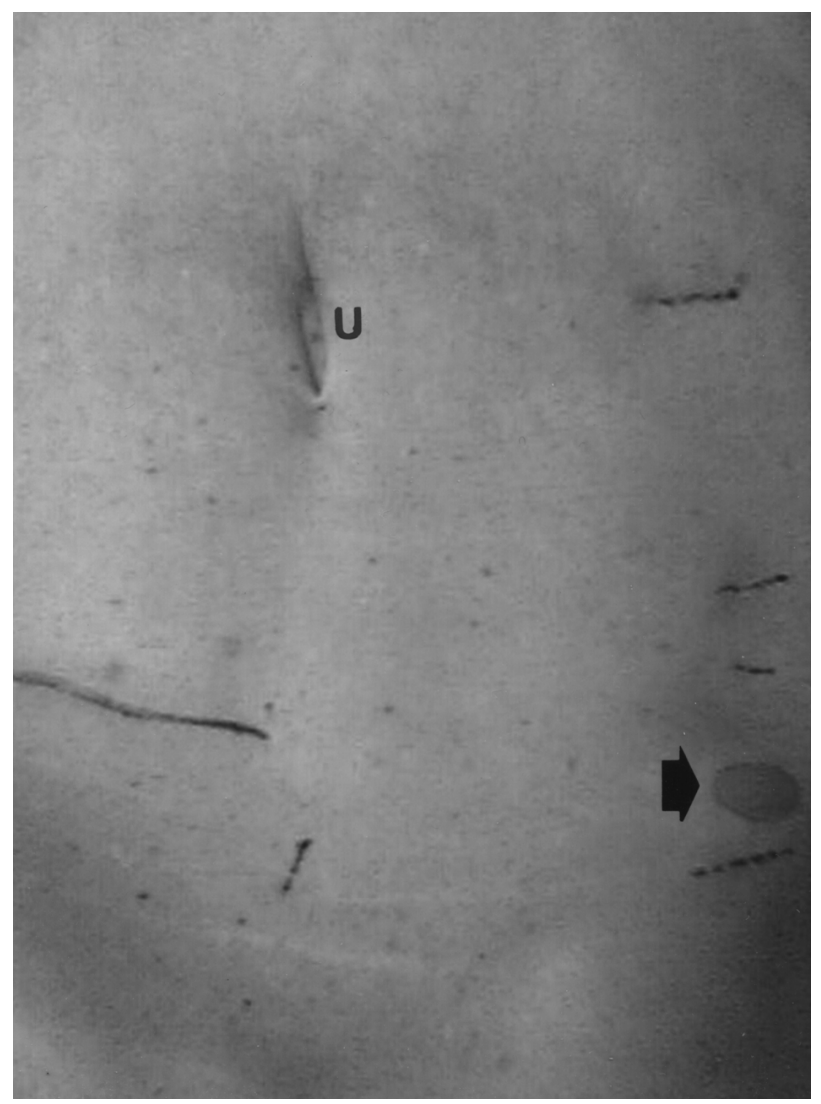

Figure 1 - The hiperpigmented skin lesion (arrow) at the region of the port site ( $U=$ umbilicus).

may improve survival (2). A potential complication of laparoscopic surgery in abdominal cancer is the possibility of tumor dissemination to the port sites, with an incidence between 0.8 and $21 \%$. Factors accounting for tumor implantation include tumor aggressiveness, immune and stress response, $\mathrm{CO}_{2}$ leakage trough trocar (chimney effect), surgeon's experience and the technique used for specimen retrieval (1). Chen et al. have recently reported the first known port site recurrence after laparoscopic adrenalectomy due to metastatic disease, in a patient with non-small cell lung cancer (3).

In this patient, the tumor was infiltrating only the muscular layer of the abdominal wall and we believe that the oblique orientation of trocar placement during the laparoscopic surgery was responsible for the fact that the hyperpigmented lesion was a few millimeters from the port site scar.
To our knowledge, this is the first description of a port site recurrence after adrenal surgery for metastatic melanoma. The possibility of port site implantation must be considered in patients with melanoma metastasis to abdominal organs who will undergo laparoscopic surgery and efforts to minimize tumor spread must be done, such as minimal tumor manipulation, avoidance of tumor boundary violation, avoidance of gas leakage, avoidance of morcellation, use of an impermeable bag for specimen retrieval and suturing $10 \mathrm{~mm}$ and larger trocar wounds (2).

\section{REFERENCES}

1. Tsivian A, Sidi AA: Port site metastases in urological laparoscopic surgery. J Urol. 2003; 169: 1213-8.

2. Cuesta Alcala JA, Caballero Martinez MC, Ripa Saldias L, Pascual Piedrola I, Solchaga Martinez A, Aldave Villanueva J, et al.: Therapeutic approach in adrenal melanoma. Review of the literature. Arch Esp Urol. 2001; 54: 685-90.

3. Chen B, Zhou M, Capelli MC, Wolf, Jr JS: Port site, retroperitoneal and intra-abdominal recurrence after laparoscopic adrenalectomy for apparently isolated metastasis. J Urol. 2002; 168: 2528-9.

Received: May 30, 2003

Accepted after revision: August 4, 2003 